\title{
FREQÜÊNCIA DAS INFECÇÕES OCULARES POR CLAMÍDIA NOS PORTADORES DE CONJUNTIVITE, EM CLÍNICA PARTICULAR DE UBERABA, MG
}

\author{
Abelardo Couto-Junior, Sérgio Murilo Corrêa, Walther Campos Filho, \\ Cleide Ozimo Bottari, Fahim Miguel Sawan, \\ José Tavares-Neto e Hélia Soares Angotti
}

\begin{abstract}
Setecentos e oitenta pacientes com recidivas clínicas de infecçoes conjuntivais ou queixas persistentes de prurido, ardor, dor, lacrimejamento e hiperemia, foram submetidos ao raspado conjuntival com citologia e pesquisa de inclusões. Destes $247(31,7 \%$ ) apresentaram inclusões citoplasmáticas; 235 pacientes foram, também, submetidos a coloração com anticorpo monoclonal fluorescente (imunofluorescência direta-DFA) com $90(38,3 \%)$ casos positivos. Discute-se também, a importância do quadro clinico e dos métodos laboratoriais (coloracào com anticorpo monoclonal fluorescente e pesquisa de inclusóes citoplasmáticas) no diagnóstico. Os pacientes fazem parte de clientela de clínica particular e tem nivel sócio-econômico de médio a alto.
\end{abstract}

Palavras-chaves: Conjuntivite. Pesquisa de inclusões por clamidia. Clamídia. Raspado conjuntival. Imunofluorescência direta.

Observa-se, comumente, na clínica oftalmologica número razoável de pacientes com conjuntivite de repetição e que, freqüentemente, è interpretada como reinfecção. No entanto, muitas vezes, é recidiva do mesmo processo infeccioso, que, quando devidamente investigado, revela, em percentagens significativas a presença de Clamydia trachomatis. Este agente etiológico associa-se com algumas doenças sexualmente transmissiveis e doenças oculares já estabelecidas como a conjuntivite de inclusão e o tracoma ${ }^{4}$.

Atualmente, nos paises desenvolvidos, a $C$. trachomatis é o agente mais comum das infecções sexualmente transmitidas, relacionando-se não somente à conjuntivites neonatais e de adultos, sexualmente ativos, mas, também, com cervicite, uretrite, salpingite, epididimite, artrite, endometrite, pneumonite e otite média 5 .

A investigação etiológica de 4260 pacientes ambulatoriais, com hiperemia conjuntival, na Ale-

Trabalho realizado na Clinica Oftalmologica Dra. Helia Angotti, Lberaba, $A . G$.

Faculdade de Medicina do Triàngulo Mineiro, Uberaba, MG.

Endereço para correspondência: Dra. Hélia Soares Angotti. Disciplina de oftalmologia. Hospital Escola/FMTM.

38025 Uberaba. MG.

Recebido para publicaçào em 11/10/89. manha Ocidental, demonstrou prevalência de infecção clamidiana de $7 \%$, com maior frequeencia no grupo etário de 20 a 25 anos 1.

No México, em estudo de 380 pacientes, detectaram $114(30,0 \%)$ com infecção oculogenital por $C$. trachomatis. Os autores ainda referem que grande número de médicos mexicanos considera a $C$. trachomatis inexistente em seu meio, e que, seus dados preliminares mostram o contrário 8 .

Em nosso meio, levantamento semelhante ainda não foi realizado. Deste modo, nosso objetivo será determinar a freqüência destas infecções oculares.

\section{MATERIAL E MÉTODOS}

No periodo de 1985 a 1989 foram atendidos em uma clinica particular (Dra. Hélia Angotti) 780 pacientes com queixas de irritação conjuntival (prurido, ardor) conjuntivite de repetição ou conjuntivite resistente ao tratamento convencional. A idade variou de 15 dias a 83 anos. O grupo pesquisado tem condição sócio-econômica situada entre as classes definidas, como média e alta, vez que tem acesso à clínica privada.

A metodologia teve a seguinte ordem de exames:
1. Exame clínico oftalmológico:
- história clínica;
- biomicroscopia, os sinais e sintomas obser- 
Couto-Junior A, Corrêa SM, Campos Filho W, Bottari CO, Sawan FM, Tavares-Neto J, Angotti HS. Freqüencia das infecções oculares por clamidia nos portadores de conjuntivite, em Clinica Particular de Uberaba, MG. Revista da Sociedade Brasileira de Medicina Tropical 23: 33-36, jan-mar, 1990.

vados e relacionados foram: hipertrofia de papilas e folículos, lacrimejamento, linfoadenomegalia (préauricular uni ou bilateral), hiperemia, ardor, prurido, dor e secreção.

\section{Exames laboratoriais:}

- exame citológico do raspado conjuntival com pesquisa de inclusão citoplasmática e determinação da celularidade 39

- coloração com anticorpo monoclonal fluorescente (exame de imunofluorescência direta - DFA) ${ }^{3}$ 7.

Dos 780 pacientes foram realizados ambos os exames em 235, visto que, somente a partir de uma determinada época passou-se a realizar o exame de coloração com anticorpo monoclonal fluorescente nos laboratórios de patologia clinica em Uberaba-MG.

Foram realizados em todos os pacientes raspados das conjuntivas tarsais superiores e inferiores de ambos os olhos utilizando-se "swab" de fio ortodôntico com algodão embebido em solução de $\mathrm{NaCl}$ a $0,9 \%$, após uso de colírio anestésico (cloridrato de proximetacaina $-0,5 \%$ ). Confeccionaram-se espécimes para citologia, do tipo "rabo de cometa" com 6 (seis) esfregaços por lâmina, sendo uma lâmina para cada olho com fixação à seco, corada pelo MayGrunwalds-Giemsa*. As lâminas para imunofluorescência foram fixadas em acetona (solução concentrada) e coradas com anticorpo monoclonal marcado com fluoresceina, ("MICROTRAK")"*; o encontro de 5 ou mais corpos elementares fluorescentes, por esfregaço, foi considerado como positivo ${ }^{6}$.

\section{RESULTADOS}

A média de idade dos 780 pacientes foi de 27 anos. Nào foi considerado o sexo no presente levantamento.

Dos 780 exames citológicos realizados, encontrou-se $247(31,7 \%)$ com presença de inclusōes citoplasmáticas. Quanto ao exame de coloração com anticorpo monoclonal fluorescente (imunofluorescência direta) realizado em 235 pacientes, 90 (38,3\%) tiveram exame positivo.

Dos 235 pacientes que realizaram exame de coloração com anticorpo monoclonal, todos fizeram exame citológico, com pesquisa de inclusões; 61 (26,0\%) pacientes tinham ambos os exames positivos e $145(62,0 \%)$ ambos negativos. Em contrapartida, de $27(11,5)$ pacientes com ausência de inclusões, a coloração com anticorpo monoclonal foi positiva; com

\footnotetext{
* Controle de qualidade para exames laboratoriais da Sociedade Brasileira de Patologia Clinica, 1985.

** Microtrak - Syva Company, Palo Alto, California.
}

dois outros pacientes ocorreu o inverso. Deste modo verificamos que a co-positividade dos testes foi de $69,3 \%$, a co-negatividade de $98,6 \%$, a concordância de $87,7 \%$ e a discordância de $12,3 \%$, como pode ser verificado na Tabela 1 .

Tabela 1 - Relação dos 235 pacientes com pesquisa de inclusões e anticorpo monoclonal fluorescente para clamidia, em Uberaba, MG.

\begin{tabular}{|c|c|c|c|c|}
\hline & & \multicolumn{3}{|c|}{$\begin{array}{l}\text { Coloraçào com anticorpo } \\
\text { monoclonal fluorescente }\end{array}$} \\
\hline & & + & - & Total \\
\hline $\begin{array}{l}\text { Pesquisa } \\
\text { de }\end{array}$ & + & $61^{a}$ & $2^{b}$ & 63 \\
\hline inclusōes & - & $27^{\mathrm{c}}$ & $145^{d}$ & 172 \\
\hline Total & & 38 & 147 & $235^{n}$ \\
\hline
\end{tabular}

co-positividade: $(a / a+c) 69,3 ;$ co-negatividade: $(d / b+d) 98,6$ concordância: $(\mathrm{a}+\mathrm{d} / \mathrm{n}) \quad 87,7 \%$; discordància: $(\mathrm{b}+\mathrm{c} / \mathrm{n})$ $12,3 \%$.

$\mathrm{Na}$ Tabela 2 os pacientes foram distribuidos conforme a faixa etária, nos grupos co-positivos $(n=61)$ e co-negativos $(n=145)$ - entre eles as faixas etárias tiveram distribuiçooes diferentes, estatisticamente $\left(X_{5}^{2}=16,96 \mathrm{p}<0,005\right)$. Por isto, cada faixa etária foi comparada com as demais, sendo na faixa etária de 0 a 10 anos a proporção de negativos significativamente maior $\left(X_{1}^{2}=8,78 p<0,005\right)$ e na de 30 a 40 anos a dos positivos $\left(X_{1}^{2}=5,39<0.02\right)$.

Tabela 2 - Distribuição dos pacientes co-positivos e conegativos para pesquisa de inclusões e coloração com anticorpo monoclonal fluorescente para clamidia, segundo a faixa etária, em Uberaba. MG.

\begin{tabular}{crrrr}
\hline & \multicolumn{2}{c}{$\mathrm{n}(\%)$} & & \\
\cline { 2 - 5 } $\begin{array}{c}\text { Faixa etaria } \\
\text { anos })\end{array}$ & $\begin{array}{c}\text { co- } \\
\text { positivos }\end{array}$ & $\begin{array}{c}\text { co- } \\
\text { negativos }\end{array}$ & $\mathrm{X}_{1}^{2}$ & $\mathrm{P}$ \\
\hline $0-10$ & $6(12,5)$ & $42(87,5)$ & 8.78 & $<0,005^{*}$ \\
$10-20$ & $8(34,8)$ & $15(65,2)$ & 0,33 & $>0,50$ \\
$20--30$ & $24(36,9)$ & $41(63,1)$ & 2,43 & $>0,10$ \\
$30-40$ & $12(50,0)$ & $12(50,0)$ & 5,39 & $<0,02^{*}$ \\
$40-50$ & $6(40,0)$ & $9(60,0)$ & $0,74^{* * *}$ & $>0,30$ \\
50 e + & $5(16,1)$ & $26(83.9)$ & 3,18 & $>0.05$ \\
\hline Total & $61(29,6)$ & $145(70,4)$ & $16,96^{* * * *}<0.005^{*}$ \\
\hline
\end{tabular}

(*) Significante; $\left({ }^{* *}\right)$ c.rreçào de Yates; $\left({ }^{* *}\right) \mathrm{g} .1 \mathrm{i}=5$. 
A presença de sinais e sintomas sugestivos de conjuntivite foi observada em todos os pacientes estudados. No entanto, nos 61 pacientes co-positivos e 145 co-negativos a distribuição dos principais sinais e sintomas foi disposta na Tabela 3. A hipertrofia de papilas e foliculos, lacrimejamento, linfoadenomeaglia e o ardor tiveram maior freqüência, estatisticamente significante, nos indivíduos co-positivos. Ao contrário, a hiperemia ocorreu mais significantamente no grupo dos co-negativos. Entretanto, o prurido, a dor e a secreção muco-purulenta tiveram distribuição semelhante nos dois grupos.

Tabela 3 - Distribuição dos pacientes co-positivos $(n=61)$ e co-negativos ( $n-145$ ) para pesquisa de inclusöes e coloraçào com anticorpo monoclonal fluorescente para clamidia, segundo ao quadro clínico.

\begin{tabular}{|c|c|c|c|c|}
\hline \multirow[b]{2}{*}{ Sinais/sintomas } & Pacientes & $\mathrm{n}(\%)$ & \multirow[b]{2}{*}{$x_{1}^{\prime \prime}$} & \multirow[b]{2}{*}{$\mathbf{P}$} \\
\hline & $\begin{array}{c}\text { co- } \\
\text { positivos }\end{array}$ & $\begin{array}{c}\text { co- } \\
\text { negativos }\end{array}$ & & \\
\hline $\begin{array}{l}\text { Hipertrofia de } \\
\text { papilas e foliculos }\end{array}$ & $45(73.8)$ & $3(2.1)$ & 123.56 & $<0.0001^{*}$ \\
\hline Lacrimejamento & $34(55.7)$ & $28(19,3)$ & 27,08 & $<0,0001^{*}$ \\
\hline Linfoadenomegalia & $32(52,5)$ & - & 90.00 & $<0.0001^{*}$ \\
\hline Hiperemia & $30(49,2)$ & $94(64,8)$ & 4,39 & $<0,05^{*}$ \\
\hline Ardor & $25(41,0)$ & $12(8,3)$ & 31.15 & $<0,0001^{*}$ \\
\hline Prurido & $19(31,2)$ & $46(31,7)$ & 0,01 & $>0,80$ \\
\hline Dor & $10(16,4)$ & $19(13,1)$ & 1,38 & $>0.50$ \\
\hline Secreçào & $7(11,5)$ & $30(20.7)$ & 2.48 & $>0,10$ \\
\hline
\end{tabular}

(*) Significante

\section{DISCUSSÃO}

A escassez de trabalhos de levantamentos relacionados a infecçōes oculares causadas por C. trachomatis no Brasil, e principalmente em nossa região (Uberaba-MG) motivou-nos à análise da casuística na clínica oftalmológica. Assim como a observação de que, curiosamente, grande número de pacientes com queixas de irritação ocular ou mesmo pacientes sem queixas especificas apresentaram quadro clínico semelhante entre si, além de resistência à medicação rotineira para conjuntivites e reincidência do quadro. Estes, quando submetidos, inicialmente, a raspado conjuntival, com análise citológica, mostraram-se, em grande número, positivos para conjuntivite de inclusão. A freqüência de $12,5 \%$ de positivos na faixa etária de 0 a 10 anos é sugestiva da importância deste agente.

Nessa região,os dados permitem supor relevância das clamidoses oculares, uma vez que, atingem po- pulações sem história aparente de contágio sexual, de faixa etária ampla (neonatos e idosos) e com características de reincidência. Assim, mostrando a importância de estudos continuados no diagnóstico etiológico das conjuntivites e sua epidemiologia.

A pesquisa destas inclusões, quando positiva, sugeriu tratar-se de clamídia; a confirmaçào por coloração com anticorpos monoclonais fluorescentes (imunofluorescência direta) se deu tão logo este exame passou a ser realizado em nosso meio. Diante desses métodos, foi possivel diagnosticar, com maior precisão, número significativo de pacientes analisados de uma clinica privada, à qual os individuos economicamente menos favorecidos têm acesso difícil.

Por sua vez, Schachter, em 1978, afirmou que, embora a conjuntivite de inclusão e o tracoma sejam duas formas de doença ocular causadas pelo mesmo microorganismo, as duas apresentações têm diferentes padrões epidemiológicos e apresentam muitas diferenças reais, em termos de relevância em saúde pública e métodos de controle 6 .

O diagnóstico através de um teste mais específico e sensível, como a coloração pelo anticorpo monoclonal fluorescente, foi progresso deciviso, porquanto as inclusões não são de tão fácil identificação. Contudo, Scarpi 6 , cita que a análise do teste de imunofluorescência depende, fundamentalmente, da experiência do examinador e do número mínimo de corpos fluorescentes que torna o exame positivo.

Ao analisar-se os resultados obtidos em 780 pacientes, vê-se que, aproximadamente um terço $(\mathrm{n}=247 ; 31,7 \%)$ dos exames realizados mostrou inclusões citoplasmáticas. Por outro lado, dos 235 pacientes submetidos ao exame de coloração com anticorpo monoclonal fluorescente $90(38,3 \%)$ apresentaram positividade para infecção clamidiana: Esta diferença de positividade entre os dois tipos de exames sugere ser significativa; traduzida pelo baixo percentual de co-positivos $(69,3 \%)$.

Quando se analisa os 235 pacientes que realizaram ambós os exames, encontrou-se $27(11,5 \%)$ com anticorpo monoclonal fluorescente positivo e não se constatou a presença de inclusões na coloração para May-Graunwalds-Giemsa, torna-se sugestivo, assim, a maior acurácia da primeira técnica, devido a maior sensibilidade e especificidade ${ }^{7}$. Por sua vez, nos dois pacientes em que se observou coloração com anticorpo monoclonal fluorescente negativa e presença de inclusões, pode-se explicar pelo fato de que a pesquisa de inclusões não é específica para clamidia, como o é a coloração pelo anticorpo monoclonal, podendo as inclusões detectadas serem, por exemplo, devido a adenovirus $^{2}$. Outra possibilidade, mesmo que infreqüente, é a de falso-negativo no exame de coloração com anticorpo monoclonal fluorescente. Esta possi- 
Couto-Junior A, Corrêa SM, Campos Filho W, Bottari CO, Sawan FM, Tavares-Neto J, Angotti HS. Freqüência das infeçōes oculares por clamídia nos portadores de conjuntivite, em Clínica Particular de Uberaba, MG. Revista da Sociedade Brasileira dé h.edicina Tropical 23: 33-36, jan-mar, 1990.

bilidade ocorre, principalmente, nos casos em que há infecção caracterizada por baixo número de organismos 7 .

Portanto, sempre que houver suspeita clínica e ausência de inclusões, deve-se fazer a pesquisa pela coloração com anticorpo monoclonal. $O$ ideal seria fazê-la em todos os pacientes, com clinica sugestiva de conjuntivite clamidiana, pois este método, alem de ser mais rápido, tem sensibilidade e especificidade comparáveis à cultura em células de $\mathrm{McCoy}^{7}$.

$\mathrm{Na}$ amostra considerada, a faixa etária de maior positividade de infecçoes clamidianas foi de 30 a 40 anos. A análise das faixas etárias permite supor maior freqüência da doença, em questão, na população sexualmente ativa, sugerindo portanto, transmissão sexual. Também é importante reenfatizar a freqüência, relativamente alta em crianças de ate 10 anos, o que contribui para considerar a endemicidade da doença, alem de outros fatores que podem ser considerados vinculados à transmissão.

Quanto ao quadro clinico, observou-se que todos os pacientes considerados apresentavam sinais e sintomas relacionados às conjuntivites. Os sinais mais relevantes nos casos positivos foram a hipertrofia de papilas e folículos e linfoadenomegalia (pré-auricular uni ou bilateral) e as queixas ardor e lacrimejamento. Enquanto a hiperemia parece estar mais relacionada aos individuos negativos.

Portanto, deve-se ressaltar, aqui, a devida importância do quadro clínico, e nāo apenas dos métodos laboratoriais para o diagnóstico da doença. Visto que em alguns pacientes, mesmo que poucos, foi a forte suspeita clínica que permitiu com que casos negativos, inicialmente, para ambos os exames, em uma segunda investigação laboratorial, fossem diagnosticados pela coloração com anticorpo monoclonal.

Tem-se a impressão de que já não é mais possível separar em terminologias especificas o tracoma en. dêmico e as conjuntivites de inclusão, ou paratracomas, sem considerar que fazem parte de uma mesma doença que, uma vez instalada, de acordo com fatores ambientais e individuais, modifica seu comportamento.

\section{SUMMARY}

780 patients with recurrent conjunctival infections or persistent complaints of itching, burning pain, lacrimation and conjunctival hyperemia were subject to conjunctival smear examination for cytology and the presence of inclusion bodies. Two hundred and forty seven (31.7\%) showed cytoplamic inclusions; 235 of them were subject to a direct specific immunofluorescency test with $90(38.3 \%)$ positive results. The inportance of the clinical manifestations and laboratory methods (direct immunofluorescence and research cytoplasmic inclusions) were considered. The patients are clients of a private clinic and have a moderate to hightor socioeconomic level.

Key-words: conjunctival infection. Research for clamydial inclusions. Chlamydia. Conjunctival sucor Direct immunofluorescence.

\section{REFERENCIAS BIBLIOGRAFICAS}

1. Bialasiewicz AA, Jahn GJ. Epidemiology of chlamydial eye diseases in a mixed rural/urban population of West Germany. Ophthalmology 93:757-762, 1986.

2. D'Angelo LJ, Hierholzer JC, Keenlyside RA, Anderson LJ, Martone WJ. Pharyngoconjunctival fever caused by adenovirus type 4: Report of a swimming pool - related outbreak with recovery of virus from pool water. Journal of Infectious Diseases 140:42-47, 1979.

3. Gupta PK, Lee EF, Erozan YS, Frost JK, Geddes ST, Donovan PA. Cytologic investigations in Chlamydia infection. Acta Cytologica 23:315-320, 1979.

4. Hallsworth PG, McDonald PJ. Detection of Chlamydia trachomatis with fluorescent monoclonal antibody. Pathology, 17:500-502, 1985.

5. Rabinovitch J, Cohen, EJ. Inclusion conjuntivites In: Inslerms, Grune Stratton (ed), AIDS and other sexualy transmitted diseases and the eye. Orlando. p. 19-36, 1987.

6. Scarpi MJ. Aspectos do tracoma em três povoados do Estado da Bahia. Tese de doutorado, Escola Paulista de Medicina, São Paulo, 1989.

7. Tam MR, Stamm WE, Handsfield H, Stephens R, Kuo CC, Holmes KK, Ditzenberger K, Krieger M, Nowinski RC. Culture-independent diagnosis of Chlamydia trachomatis using monoclonal antibodies. The New England Journal of Medicine 310:1 146-1150, 1984.

8. Tovar FT, Valls-De-Ruiz M, Araiza JI, Ruiz-Arguelles A. Infecciones oculogenitales por Chlamydia trachomatis en la ciudaa de Puebla (Letter). Revista de Investigacion Clinica (Méx.), 36:391, 1984

9. Woodland RM, Malam J, Darodugar S. A rapid method for staining inclusions of Chlamydia psittaci and Chlamydia trachomatis. Journal of Clinical Pathology. 35:642:644, 1982. 